\title{
Estimation of appropriate power range extender for battery electric vehicle
}

\author{
A. N. Tikhomirov ${ }^{1, *}, O$. B. Tikhomirova ${ }^{1}$, and M. E. Gnenik ${ }^{1}$, and V. Gropa ${ }^{2}$ \\ ${ }^{1}$ Nizhniy Novgorod State Technical University, Nizhniy Novgorod, Russia \\ 2 Technical University of Moldova, Moldova
}

\begin{abstract}
The article presents the results of an experimental and theoretical study of the energy consumption of a vehicle under different conditions. The purpose was to determine the power of the auxiliary range extender on board of the electric battery vehicle. Driving is considered both for real road conditions of a large city, and a specific driving cycle. The high validity of the results is ensured by the use of the new driving cycle WLTC. It is shown that in urban traffic conditions $5 \mathrm{~kW}$ auxiliary power plant is sufficient for adequate compensation of electricity consumption of a vehicle with a curb weight $2500 \mathrm{~kg}$.
\end{abstract}

\section{Introduction}

Even though the share of electric vehicles today account for about $0.5 \%$, there is already a mismatch between the electric transport development and the existing energy infrastructure [1-4]. Unlike electric vehicle battery systems, power generation is a well-established technology, and while the laws of energy transfer remain largely unchanged [5-10]. If the use of electric transport should be considered as a recipe for reducing the environmental impact on cities, then it is generally in large centers that existing power grids operate at their limits not allowing for higher transmission of electric power [11].

The way out is seen in the generation of electricity directly onboard the vehicle. The use of so-called range extender does not contradict the general concept of the electrical transport. A vehicle, which can be multitonnage, can enter city centers on electric traction without polluting the air and avoiding tolls. Electricity mileage may be small, about $50 \mathrm{~km}$, but in most cases this is sufficient for transport operation. If you are out of the center, the auxiliary power plant is turned on to recharge the batteries, and the only issue remaining is its efficiency and environmental friendliness. A compromise is reached between traditional and innovative technologies.

What can be the source of auxiliary energy? Any system that convert the chemical energy of traditional fuel into electrical energy. In most cases electricity is generated directly by an electrodynamics alternator. But a thermal engine serves as an intermediate link in the conversion of chemical energy to mechanical energy - a conventional reciprocating internal combustion engine, a gas turbine or an external combustion engine. Fuel cells allow for elimination of intermediate thermal and mechanical energy transformations. Their advantages include high fuel efficiency, low noise and vibration, high maneuverability for the whole range of loads. Their disadvantages are dependence on expensive hydrogen, freezing water problems and high cost.

For a vehicle with conventional power transmission to the wheels, the engine power is selected to achieve the specified maximum vehicle speed and the desired acceleration dynamics. Hybrid cars are equipped with ICE of reduced power, with acceleration reliant for a short time on the electric drive and energy stored in the batteries. In electric vehicles the auxiliary power system cannot help the movement, and its output must be chosen according to the average power of the vehicle movement for a certain cycle.

\section{Methods and materials}

It is not advisable to use a high power auxiliary power plant. The maximum speed and dynamics of the vehicle are provided by the energy stored in the batteries. Also, in the urban environment where the main operation of electric vehicles is planned, the share of maximum loads is extremely small, while the share of stops and low speeds is high.

\subsection{Experimental Setup}

Figure 1, for example, presents a fragment of recorded parameters of the LCV A21R22, moving with a gross mass of $3,500 \mathrm{~kg}$ in a large city, and in Figure 2 the power taken from the engine in these conditions. Parameters of the vehicle movement (Racelogic VBOX3i $100 \mathrm{~Hz}$ ) and data from the engine control unit (CAN) were recorded. The route, which was about 100 meters, started and ended at one point to avoid the effect of the elevation difference. The total length of the route was $42.5 \mathrm{~km}$, with the average speed of $26.3 \mathrm{~km} / \mathrm{h}$, and

\footnotetext{
* Corresponding author: its@nntu.ru
} 
the maximum acceleration up to $3 \mathrm{~m} / \mathrm{s} 2$. The data was recorded for 6090 seconds, but for convenience of comparison with the calculated cycle given below, only the fragments of $1500 \mathrm{~s}$ recording are represented in the figures.

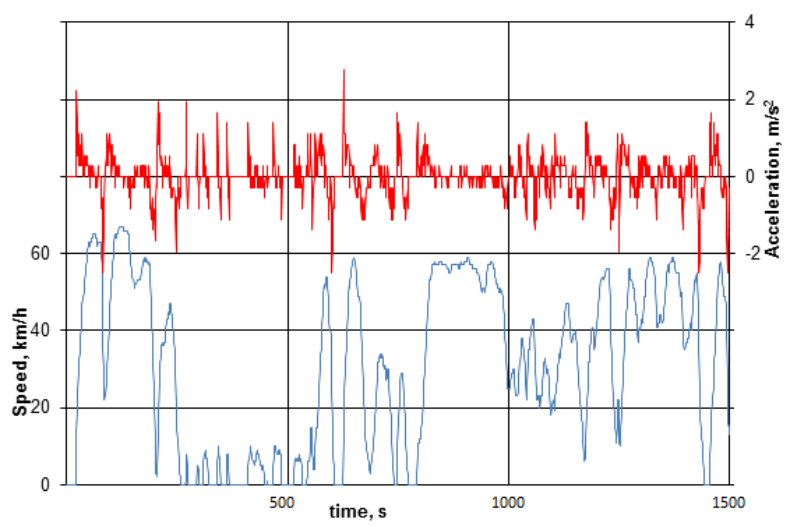

Fig. 1. City driving fragment of recording.

It can be seen that only in a short section of the route (from 820 to 980 seconds when the vehicle overcame a prolonged uphill climb), the power remained in the range of about $25 \ldots 30 \mathrm{~kW}$. Over the rest of the route, the power demand was impulsive, and mostly on acceleration of the vehicle. The maximum achieved engine power was $60 \mathrm{~kW}$. Also, 15 peaks of $55 \mathrm{~kW}$ power were observed. Energy used for the movement along the full cycle was $67,560 \mathrm{~kJ}$ which corresponds to an average engine power of $11.1 \mathrm{~kW}$.

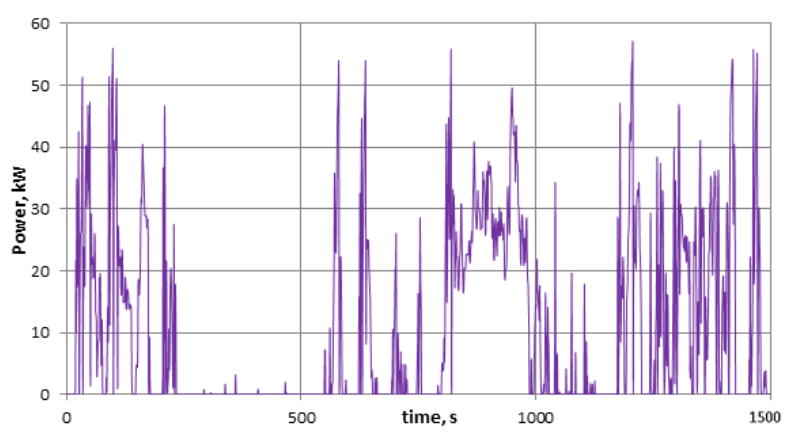

Fig. 2. Engine output for city driving (fragment).

For a diesel engine of this vehicle with a mechanical transmission, the same power can be achieved in different operation modes. The effectiveness of modes could be higher or lower, and the choice is due only to the preferences and temperament of the driver. This is well illustrated by Figure 3 which shows all ICE operation mode points on the route.

\subsection{Data Analysis}

To avoid the impact of certain ranges, possible differences in measurements depending on the driving style, the energy costs analysis should be carried out according to standard driving cycles. Each of these represents a known dependence of the speed of motion versus time. The most common is the European driving cycle NEDC imitating the movement both in the city (the first part of the cycle) and outside the city (the second part of the cycle). However, it was built more than half a century ago and became absolutely uncharacteristic of modern traffic conditions. In the urban phase of the cycle, the maximum speed is 50 $\mathrm{km} / \mathrm{h}$, with the average speed of about $18 \mathrm{~km} / \mathrm{h}$ and maximum acceleration of about $1 \mathrm{~m} / \mathrm{s}^{2}$.

As an alternative to the European cycle, experts from the EU, Japan and India have developed a new WLTP test procedure (Worldwide Harmonized Light Vehicles Test Procedures) [12]. The main purpose here is to assess the operational fuel efficiency of a vehicle that is fully characterized by $\mathrm{CO}_{2}$ emissions. The procedure involves three possible test classes with the corresponding WLTC test cycles, depending on the vehicle's power output. The ratio of the rated power of the engine to the curb weight of the vehicle (PWR) was chosen as a criterion.

Most modern vehicles with ICE fall into the third class with specific power of PWR $>34 \mathrm{~kW} / \mathrm{t}$. The specific power of the LCV A21R22 with a $96 \mathrm{~kW}$ diesel engine considered in the first case was $48 \mathrm{~kW} / \mathrm{t}$. In contrast, the electrical vehicles feature a relatively large curb weight disproportionate to the power of the electric drive, especially with and auxiliary range extender.

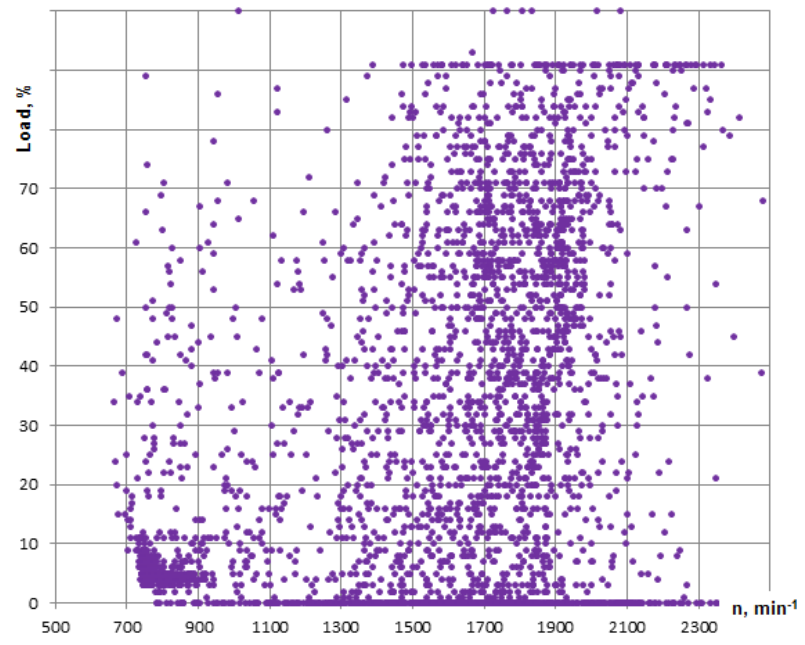

Fig. 3. Engine mode map for city driving.

The analysis of 12 electric light commercial trucks showed that one third of them falls only in the second class with PWR $<34 \mathrm{~kW} / \mathrm{t}$. Moreover, the maximum speed does not exceed $90 \mathrm{~km} / \mathrm{h}$. For such vehicles, a truncated cycle of class 2 WLTC is provided (Figure 4), which does not contain the Extra High 2 section.

When comparing the real cycle in the city and the WLTC class 2 cycle, one can note their considerable similarity. This confirms the correctness of the choice of the WLTC procedure for an objective assessment of vehicles in operation. Of course, the WLTC cycle is less dynamic; the maximum acceleration does not exceed 1 $\mathrm{m} / \mathrm{s}^{2}$, with the maximum speed of $84 \mathrm{~km} / \mathrm{h}$. But the reduced dynamics is set here based on a twofold difference in the power-to-weight ratio of the vehicle. In the first case PWR $=48 \mathrm{~kW} / \mathrm{t}$, in the second case PWR was only $=22 \mathrm{~kW} / \mathrm{t}$. 
Here are the estimated WLTC cycle for a gross vehicle weight of $3500 \mathrm{~kg}$ (curb weight $2500 \mathrm{~kg}$ ). The dynamometer is simulated in accordance with ECE Regulations 83. The total cycle time is 1477 s. Energy used on the vehicle movement along the full cycle is $6864 \mathrm{~kJ}$ which corresponds to an average engine power of $4.65 \mathrm{~kW}$.

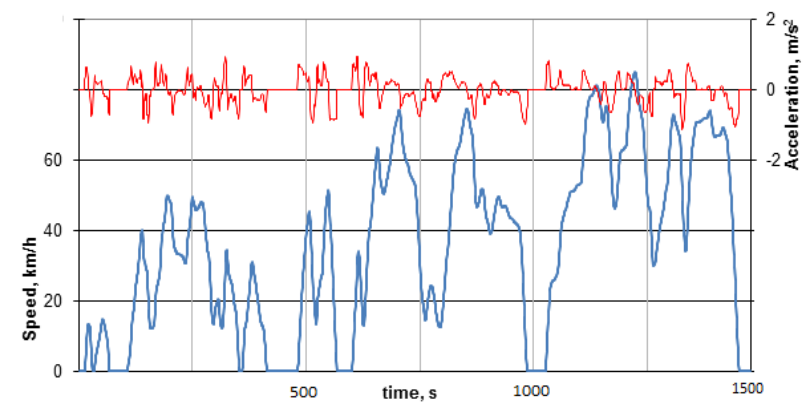

Fig. 4. WLTC class 2 driving cycle for vehicles with maximum speed below $90 \mathrm{~km} / \mathrm{h}$.

One more driving cycle developed for the urban routes in Kuala Terengganu, Malaysia should be mentioned [13]. It is developed using genetic algorithms, taking into account urban driving characteristics. Its total time of 1600 seconds is comparable to the well-known WLTC. Comparable are both the maximum speed of the cycle and the maximum acceleration. An approximate analysis of energy costs for a vehicle with a curb weight of $2500 \mathrm{~kg}$ along this cycle showed an average power of $5.2 \mathrm{~kW}$. Do not count on its mass distribution, but for our case it is very revealing. It can be assumed that any modern driving cycle, generated both by calculation, or recorded on the road, will give approximately the same results for energy costs.

\section{Results and discussion}

The difference in the average cycle power $(4.65 \mathrm{~kW}$ versus $11.1 \mathrm{~kW}$ ) is in good agreement with the difference in the required dynamics of the cycles used (1 $\mathrm{m} / \mathrm{s}^{2}$ vs. $3 \mathrm{~m} / \mathrm{s}^{2}$ ), and allows to select the power of the auxiliary power plant sufficient for maintenance electrical vehicle. So for a curb weight $2500 \mathrm{~kg}$ and an electric drive output of $55 \mathrm{~kW}(\mathrm{PWR}=22 \mathrm{~kW} / \mathrm{t})$, the auxiliary power plant should have a power of $5 \mathrm{~kW}$. The vehicle probably will not be able to stay in the modern urban traffic flow. However, continuous operation charging of such power would completely compensate electricity consumption for traffic. Before the using up the fuel on board, the vehicle will be able to maintain mobility without connecting to the power socket. True, the vehicle is no longer electric in the full sense. But at the same time, the capacity and mass of the traction batteries can be significantly reduced, making room for payload.

Electric vehicles today are focused on the power endurance of $100 \ldots 200 \mathrm{~km}$. This choice is based on the rational use of the working time of the vehicle and its driver, on the statistical analysis of the delivery fleet of light commercial vehicles. Today best lithium-ion batteries power feature about $250 \mathrm{~W} * \mathrm{~h} / \mathrm{kg}$, and the electricity consumption of electric vehicles with a gross weight of about $3,500 \mathrm{~kg}$ is about $300 \mathrm{~W} * \mathrm{~h} / \mathrm{km}$ [14]. Therefore, a battery station weighing about $200 \mathrm{~kg}$ should be provided on board. An auxiliary power plant easily saves the specified daily mileage; excludes idle runs to the filling station and back. Electricity mileage can be reduced to $50 \mathrm{~km}$, which may be sufficient to service "green" zones in the centers of megapolices. Accordingly, the weight of the batteries is reduced by three times. Do not forget about the total cost of installed batteries. In recent years the price of batteries has decreased almost fivefold but still remains to be one of the limiting factors for the spread of electric transport.

If the actual traffic conditions do not match with the estimations (suburban routes, aggressive driving, aspiration to follow the traffic flow), the accepted power of the auxiliary power plant will no longer be able to fully cover energy costs immediately during the journey. With an average movement power of $11 \mathrm{~kW}$, as in the first example, even the continuous operation of the $5 \mathrm{~kW}$ auxiliary power plant will cover only half of the electricity consumed. The depletion of the batteries will lead to the need to either reduce the maximum speed or dynamics of the vehicle, to continue driving, or at least stop completely to recharge the batteries. In any case, it should be remembered that we discuss an electrical vehicle, and in such situation one should go to the nearest electric charging station.

\section{Conclusions}

While programs to subsidize private charging stations and the development of the state network of charging stations are not implemented, a back-up path of development for electric vehicles should be maintained. There should be support for clean technologies of electric transport by charging the batteries on board the vehicle using proven technical means. Such as auxiliary power generation systems based on thermal engines or fuel cells. The use of such systems will reduce the number of batteries on board, or replace them with cheaper and more affordable, but of lower capacity. Regarding the power of the auxiliary power unit, the analysis of the movement along the WLTC cycle showed that the average power consumption on traffic does not exceed $5 \mathrm{~kW}$ for the second class power-carrying vehicles. If this level provides complete independence of charging stations, then for heavier load operating conditions, the auxiliary power plant of $5 \mathrm{~kW}$ will partially cover the energy consumption, as it has been planned. For the vehicle power output of about $48 \mathrm{~kW} / \mathrm{t}$, the continuous activation of an auxiliary power plant can compensate for half of the energy consumption, or all energy, which, however, involves interruptions of the vehicle movement $50 \%$ of the time.

This research is performed with the financial support from Ministry of Science and Higher Education of the Russian Federation (the unique project identifier is RFMEFI57717X0268). 


\section{References}

[1] L.V. Plotnikova, R.R. Giniyatov, S.Y. Sitnikov, M.A. Fedorov, R.S. Zaripova, Perfection of the methodology for developing industrial secondary energy generation systems, IOP Conference Series: Earth and Environmental Science, 288(1),012069 (2019)

[2] E. Sukhareva, A. Fedyukhin, O. Derevianko, M. Egorov, L. Mukhametova, I. Akhmetova, Optimization of combined heat and power plant operating mode by means of underutilized equipment mothball, IOP Conference Series: Earth and Environmental Science, 288(1),012122 (2019)

[3] T.I. Petrov, A.R. Safin, I.V. Ivshin, L.V. Dolomanyuk, M.F. Nizamiev, Control station based on synchronous motors, IOP Conference Series: Earth and Environmental Science, 288(1),012111 (2019)

[4] V.I. Sitas, A.V. Fedyukhin, I.G. Akhmetova, A. Mitrofanov, S.O. Makoev, A. Asadpoori, A.A. Sinitsyn, E.A. Kikot, Assessment of technical and economic efficiency indicators of cogeneration in modern market conditions, International Journal of Civil Engineering and Technology, 10(2), 2106-2117 (2019)

[5] E. Shaburov, A. Fedyukhin, O. Derevianko, Analysis of Energy Efficiency of Municipal Solid Waste Usage for Thermal and Electrical Energy Production, IOP Conference Series: Earth and Environmental Science, 272(2),022105 (2019)

[6] N. Huang, P. Zhao, S. Ghosh, A. Fedyukhin, Cohydrothermal carbonization of polyvinyl chloride and moist biomass to remove chlorine and inorganics for clean fuel production, Applied Energy, 240, 882-892 (2019)

[7] E.I. Gracheva, O.V. Naumov, Estimation of power losses in electric devices of the electrotechnical complex, 2019 International Conference on Industrial Engineering, Applications and Manufacturing, ICIEAM 2019, 8742923 (2019)

[8] E.I. Gracheva, O.V. Fedorov, Forecasting reliability electrotechnical complexes of in-plant electric power supply taking into account low-voltage electrical apparatuses, 2019 International Conference on Industrial Engineering, Applications and Manufacturing, ICIEAM 2019, 8743057 (2019)

[9] A.R. Safin, R.R. Khusnutdinov, A.M. Kopylov, The method topological optimization for design linear electric machines, 2019 International Science and Technology Conference "EastConf", EastConf 2019, 8725379 (2019)

[10] D. Barsi, C. Costa, F. Satta, P. Zunino, V. Sergeev, Feasibility of mini combined cycles for naval applications, MATEC Web of Conferences, 245,07008 (2018)

[11] $C B C$ News - Retrieved from: http://www.cbc.ca/news/canada/toronto/ontario-hopesrevised-condo-act-ev-friendly-1.4155747, (2018)

[12] European commission - Retrieved from: https:/circabc.europa.eu/sd/a/b40f7...2018.05.2012.pdf; 25 February, (2018)

[13] I.N. Anida, I.S. Ismail, J.S. Norbakyah, W.H. Atiq, A.R. Salisa, Characterisation and development of driving cycle for work route in Kuala Terengganu. International
Journal of Automotive and Mechanical Engineering; 14, 3 4508-4517 (2017)

[14] Battery University - Retrieved from: http://www.batteryuniversity.com; 25 February, (2018) 